\title{
The Health Profile of People Living with Parkinson's Disease Managed in a Comprehensive Care Setting
}

Meg E Morris ${ }^{1}$, Anna T Murphy ${ }^{2,3^{*}}$, Jennifer J Watts ${ }^{4}$, Damien Jolley ${ }^{3}$, Donald Campbell ${ }^{3}$, Sze-Ee Soh ${ }^{5,8}$, Catherine M Said ${ }^{1,6}$ and Robert lansek $^{2,3}$

${ }^{1}$ Department of Physiotherapy, La Trobe University, Victoria, 3086, Australia

${ }^{2}$ Kingston Centre, Monash Health, Cheltenham, 3192, Australia

${ }^{3}$ Faculty of Medicine, Nursing and Health Sciences, Monash University, Victoria, 3800, Australia

${ }^{4}$ School of Health and Social Development, Deakin University, Burwood, 3125, Australia

${ }^{5}$ Physiotherapy Department, Alfred Health, Caulfield, 3162, Australia

${ }^{6}$ Department of Physiotherapy, Austin Health, Heidelberg, 3084, Australia

${ }^{7}$ Department of Physiotherapy, The University of Melbourne, Parkville, 3010, Australia

${ }^{8}$ Department of Physiotherapy and Health Services Research Unit, Monash University, Victoria, 3004, Australia

*Corresponding author: Murphy AT, Kingston Centre, Monash Health, Cheltenham, 3192, Australia, Tel: +61-3-9265-1453; Fax +61-3-9265-1577; E-mail: AnnaT.Murphy@monashhealth.org

Received date: November 26, 2014; Accepted date: June 15, 2015; Published date: June 22, 2015

Copyright: ( 2015 Morris, et al. This is an open-access article distributed under the terms of the Creative Commons Attribution License, which permits unrestricted use, distribution, and reproduction in any medium, provided the original author and source are credited.

\begin{abstract}
Background: Globally there are few reports of the impairments, disabilities and medications used in people living with idiopathic Parkinson's disease. Caregiver characteristics and caregiver burden have seldom been reported. We examined the health status in a large cohort of people living with Parkinson's disease and their caregivers managed in a comprehensive health care setting.

Methods/Design: A prospective, cross sectional analysis of impairments, disabilities and Parkinson's disease medication use was conducted in a sample of 100 people with Parkinson's disease rated I-IV on the modified Hoehn \& Yahr scale. Participants were recruited from the Victorian Comprehensive Parkinson Program in Melbourne, Australia. Their caregivers were invited to provide their views on the burden of care, services provided and support received.
\end{abstract}

Results: The severity of impairments and disabilities was strongly associated with disease duration (mean of 5.5 years). Those with long standing disease or more severe disease also used more Parkinson's disease medications and participated in fewer social roles than people who were newly diagnosed or mildly affected. The severity of impairments was strongly correlated with limitations in performing activities of daily living. Limitations in performing daily activities were also found to be a significant contributing factor for health-related quality of life (PDQ-39 SI $\beta=0.55, p=0.000$; EQ-5D SI $\beta=0.43, p=0.001$ ). People with Parkinson's disease lived at home with relatives. The average caregiver was a spouse or child providing approximately 3.5 hours of care per day, with the capacity to provide 9.4 hours per day and had provided care for four years. Additional support was high (63\%) for 2.5 hours per day.

Conclusion: The comprehensive care setting of this cohort describes a relatively benign condition despite a wide range of disease duration and severity. This report provides a baseline with which to compare other delivery models.

Keywords: Parkinson disease; Australia; Comprehensive care

\section{Introduction}

Parkinson disease (PD) is a degenerative and progressive disorder that mainly affects older people [1]. The rapid population ageing throughout developed countries means that the number of people diagnosed with PD will increase to over 10 million by 2050 [2]. Elderly people have an additional disease debt that accompanies the legacy of advanced age, making people with $\mathrm{PD}$ very prone to complications such as falls, pneumonia and psychosis, adding to the already high social and economic burden of the disease [3].
The symptoms of Parkinson's disease are significant. Parkinson's disease affects the size and speed of automatic sequential movements such as walking, standing, moving from one position to another, manipulating objects with dexterity, speaking and swallowing [4]. It also affects automatic control of cognition, mood and behaviour [5]. Dysfunction is associated with difficulty with instrumental activities of daily living (ADL) such as driving and self-care. Eventually the disease can involve other brain areas that control bowel, bladder, blood pressure, sleep and cognition [6].

Although no cure currently exists, treatment is available for the symptoms of PD, particularly for movement disorders. These benefits diminish over the longer term and unwanted fluctuations develop [7]. For these reasons, an inter-professional team approach has been 
Page 2 of 7

advocated for the management of the complex array of disorders of movement, cognition and autonomic function $[8,9]$. The aim is often to limit the rate and level of disease progression and to enable people with PD and others in their lives to enjoy the highest possible quality of life.

Little information is available that describes the average person with Parkinson, taking into consideration the effects of duration of disease and its increasing morbidity. Typically cohorts of patients are described according to a specific intervention with the focus on the outcome of that intervention. No studies have described the status of patients under normal care, but particularly in relation to different care models and across a range of settings.

This paper describes a cohort of patients referred to the Victorian Comprehensive Parkinson Program (VCPP). It provides a snapshot of health, impairments, activity limitations, health-related quality of life (HRQOL) and caregiver requirements when referred to the Program, and as such provides a baseline for future outcome measures. It provides very basic information, which is unfortunately commonly forgotten in the quest for novel interventions, but nevertheless is important to provide a normal perspective of the impact of Parkinson's disease.

\section{Methods}

Recruitment to this study was based on a convenience sample of newly referred people with PD to the VCPP in Melbourne, Australia and their caregivers. This included referrals from a large geographical area comprising metropolitan Melbourne, regional and rural Victoria and Tasmania in Australia (80 separate postcodes). To be included, participants were required to have a diagnosis of idiopathic PD confirmed by a neurologist and be willing and able to give informed consent. When a person with PD had cognitive impairment (Minimental State Examination (MMSE) [10] <24/30), caregiver consent for participation was required. Additional consent for access to Medicare Australia claims data was requested, yet not mandatory. People were excluded if they were severely disabled [11] (Stage V), had little to no English language skills, or if they had co-existing neurological, musculoskeletal or cardiopulmonary conditions that produced significant motor or cognitive impairments that prevented them from being tested. The study was approved by the Monash Health Human Research Ethics Committee (HREC Number 06107B) and the Monash University Standing Committee on Ethics in Research Involving Humans (SCERH No. 2006/728MCC) of Australia.

All patients who were referred to the principal investigator (RI) were considered for participation based on their eligibility to meet the inclusion criteria. The demographics of the participating cohort revealed that the age distribution, sex ratio, duration of disease and severity (as rated according to the modified H\&Y Scale) were similar to published prevalence studies [12,13] and incorporated the broad extent of the PD timeline and its associated severity ratings. Overall the cohort can be considered to be a representative sample of the condition in the Australian context.

After informed consent was received, the baseline measurements were obtained [14]. These are listed in Table 1 with the maximum score for each test. A registered physiotherapist or medical practitioner performed the measurements in the home setting, at the Kingston Centre Movement Disorders Clinic or at a local clinic. Participants were also requested to complete a medication diary over two consecutive days immediately after the visit. Participants with cognitive impairment were assisted by their caregiver to answer the questionnaires and complete their medication diaries.

\begin{tabular}{|c|c|c|}
\hline Clinical Measures & Variable & Maximum Score \\
\hline Hoehn \& Yahr Scale (H\&Y) & $\begin{array}{l}\text { Disease } \\
\text { severity }\end{array}$ & $5^{*}$ \\
\hline $\begin{array}{l}\text { United Parkinson's Rating Scale (UPDRS) } \\
\text { Section I (Mentation, behaviour and mood) } \\
\text { Section II (Activities of Daily Living) } \\
\text { Section III (Motor Skills) } \\
\text { Section IV (Complications of therapy) }\end{array}$ & Disability & $\begin{array}{l}16^{*} \\
43^{*} \\
56^{*} \\
23^{*}\end{array}$ \\
\hline Schwab \& England (\%) & Disability & 100 \\
\hline Modified Dyskinesia Rating Scale & Dyskinesia & $4^{*}$ \\
\hline Parkinson's Disease Questionnaire (PDQ39) & HRQOL & $100^{*}$ \\
\hline EUROQOL-5D-3L (EQ-5D-3L) & HRQOL & 1 \\
\hline EUROQOL Visual Analogue Scale (EQ VAS) & HRQOL & 100 \\
\hline $6 \mathrm{~m}$ walking test (secs) & Mobility & * \\
\hline Timed Up \& Go (TUG) (secs) & Mobility & * \\
\hline Parkinson Disease Fatigue Scale (PFS) & Fatigue & 100 \\
\hline Geriatric Depression Scale & Depression & $15^{*}$ \\
\hline $\begin{array}{l}\text { Neuro-psychiatric inventory } \\
\text { Severity } \\
\text { Distress }\end{array}$ & $\begin{array}{l}\text { Caregiver } \\
\text { burden }\end{array}$ & $\begin{array}{l}36^{*} \\
60^{*}\end{array}$ \\
\hline $\begin{array}{l}\text { Motor fluctuation diary for previous 24-48 } \\
\text { hours }\end{array}$ & Fluctuations & $\mathrm{N} / \mathrm{A}$ \\
\hline \multicolumn{3}{|l|}{ HRQOL-Health-related quality of life. } \\
\hline${ }^{*}$ The maximum score/time indicates the mos & ere ir & \\
\hline
\end{tabular}

Table 1: Clinical measures assessed and the corresponding variable.

A caregiver interview was conducted by an experienced general practitioner and was performed face-to-face with the caregiver only. The interview focussed on three main areas; the amount and level of care needed by the help recipient, support services used by the care recipient and economic information on such things as employment, informal and formal assistance and government allowances. A total of 24 questions regarding the care needs of the recipient were recorded on a scale of 1-4 (1=requires no assistance, $4=$ requires a lot of assistance). The questions were categorised into personal ADL, domestic ADL, community engagement, cognitive related assistance and social support.

Summary statistics including number of participants, mean, standard deviation (SD), median and range were calculated for all continuous variables. When subgroup analysis was undertaken $95 \%$ confidence intervals around the mean are reported. Univariate and multivariate regression analyses were performed to explore the relationships between impairments, activity limitations and HRQOL. The dependent outcome variables were overall HRQOL as measured by the Parkinson's Disease Questionnaire-39 summary index (PDQ-39SI) and EuroQoL summary index (EQ-5DSI). Independent variables included in the analyses were disease severity as measured by 
Citation: Morris EM, Murphy AT, Watts JJ, Jolley D, Campbell D, et al. (2015) The Health Profile of People Living with Parkinson's Disease Managed in a Comprehensive Care Setting. Aging Sci 3: 135. doi:10.4172/2329-8847.1000135

Page 3 of 7

the modified H\&Y scale, disease duration, activity limitations as measured by the Unified Parkinson's Disease Rating Scale (UPDRS) Activities of Daily Living (ADL), depression as measured by the Geriatric Depression Scale (GDS), fatigue as measured by the Parkinson Disease Fatigue Scale (PFS), neuropsychiatric symptom severity as measured by the Neuropsychiatric Inventory (NPI) scale and cognitive impairment as measured by the MMSE. Disease severity was classified as mild (stages $\leq 2$ ) and moderate severity (Stages $\geq 2.5$ ) given the ordinal nature of the modified H\&Y scale [15]. All other variables were treated as continuous variables. An initial evaluation of the assumptions of the regression analyses led to a powered transformation of the dependent variables (PDQ39SI and EQ-5DSI) to improve the normality and linearity of residuals. Disease duration, activity limitations, depression, cognitive impairment and neuropsychiatric symptom severity were also transformed to further reduce skewness and the number of outliers.

Univariate and multivariate regression analyses were also performed to examine whether the type of caregiver contributed to the HRQOL of care recipients. Independent variables included in this set of analyses were disease severity as measured by the modified H\&Y scale, living situation and carer type (partner, family member or friend). All analyses were conducted using SPSS v20.0 (SPSS Inc, Chicago, IL).

\begin{tabular}{|c|c|c|c|c|}
\hline \multirow[t]{2}{*}{ Variable } & \multicolumn{2}{|l|}{ Community } & \multicolumn{2}{|l|}{ Supported Care } \\
\hline & Mean (St Dev) & Range & Mean (St Dev) & Range \\
\hline Sex frequency* $M / F$ & $57 / 36$ & - & $4 / 3$ & - \\
\hline Age (years) & $69.2(9.7)$ & $43-89$ & $73.1(5.6)$ & $64-83$ \\
\hline BMI (kg/m2) & $26.1(5.4)$ & $16.6-52.8$ & $24.3(2.2)$ & $21.8-28.2$ \\
\hline PD duration (years) & $5.8(5.2)$ & $0-21$ & $9.5(6.0)$ & $0-20$ \\
\hline $\begin{array}{l}\text { Severity }(H \& Y \text { Stage })^{a} \\
\text { Stage } 1(\%) \\
\text { Stage } 1.5(\%) \\
\text { Stage } 2(\%) \\
\text { Stage } 2.5(\%) \\
\text { Stage } 3(\%) \\
\text { Stage } 4(\%)\end{array}$ & $\begin{array}{l}2.3(0.9) \\
22 \\
2 \\
15 \\
26 \\
19 \\
10\end{array}$ & $1-4$ & $\begin{array}{l}3.1(1.1) \\
1 \\
0 \\
0 \\
1 \\
2 \\
2\end{array}$ & $1-4$ \\
\hline MMSE (Score) & $27.5(3.5)$ & $12-30$ & $24.3(5.7)$ & $14-30$ \\
\hline Co-morbities (count) & $4.8(2.5)$ & $0-12$ & $4.9(1.1)$ & $3-6$ \\
\hline Fatigue (ordinal score) & $45.7(13.2)$ & $17-74$ & $49.2(12.4)$ & $33-66$ \\
\hline Depression (score) & $4.4(3.7)$ & $0-14$ & $5.8(2.6)$ & $3-9$ \\
\hline $\begin{array}{l}\text { Neuro-psychiatric inventory of caregiver } \\
\text { burden (count) }\end{array}$ & $3.0(2.6)^{b}$ & $0-11$ & $4.5(3.3)^{c}$ & $0-8$ \\
\hline \multicolumn{4}{|c|}{$\begin{array}{l}\text { aMean, standard deviation and range presented for modified Hoehn and Yahr stage followed by percentage of patients at each stage. } \\
\text { bFive participants did not have a caregiver. }\end{array}$} & \\
\hline
\end{tabular}

Table 2: Population demographics.

\section{Results}

\section{Demographic characteristics}

The first consecutive 198 people referred to the VCPP over a 22month period were considered for the study. Forty-eight people did not meet the inclusion criteria and were not invited to participate. Of the remaining 150, 100 were willing and eligible to be in the trial. Reasons for non-enrolment included disinterest (50\%), time commitment $(22 \%)$, person felt they were too unwell $(16 \%)$, or emotional distress (10\%).
Most of this Australian sample were married (67\%) and 93\% of participants lived in the community either on their own (16\%) or with others (including spouse/partner, child, friend). The remaining $7 \%$ lived in supported care; hostel or nursing home. Further detailed analysis of data by setting was not feasible due to the small participant numbers living in supported care. The demographic and PD information of the participating cohort are summarised in Table 2.

Fourteen participants had a MMSE score less than 24, which is consistent with dementia. To some degree this was also reflected within the UPDRS [16] cognition and behaviour score with a mean value of 2.8 (SD2.4) and a range of 0-10. The NPI Caregiver Burden 
[17] revealed that 14 participants did not have any neuropsychiatric disturbances and that the remainder experienced up to 11 neuropsychiatric disturbances (maximum possible on the questionnaire). The most frequent types of disturbance related to mood change, apathy, appetite change, agitation, irritability, anxiety, depression and night time behaviours. Depression was not reported for most participants, with only 14 reports of depression. The most common co-morbidities were musculoskeletal (69\%), cardiovascular (50\%), gastrointestinal (35\%) renal or genito-urinary (32\%), allergies $(33 \%)$ and psychiatric (30\%).

\section{Profile of impairments, activity limitations and health- related quality of life in Australians with PD}

Table 3 summarises the motor impairments, activity limitations and HRQOL of the participants. Eighty-nine of the participants with PD were able to complete the 6 metre walk without assistance or assistive devices, suggesting most people in this sample had only relatively mild gait impairments. Ninety-one people with PD were able to complete the Timed "Up \& Go" Test (TUG) [18]. The mean value of 11.8 seconds (SD 5.8, range 5.6-40.2) is within the normal range for older people reported by Morris and colleagues [19] of 7.03-12.66 seconds. There were a small number of outliers who performed this sequential motor task very slowly. The motor sub-component of the UPDRS (Section III) also indicated that the sample as a whole was comparatively mildly disabled.

The ability to perform ADL was also mildly or moderately compromised for most people, as seen by the UPDRS ADL and Schwab \& England (S\&E) [20] ADL scores in Table 3. Assistance was required for activities such as showering (36\% of participants required assistance with this at least some of the time), dressing (55\%), toileting $(20 \%)$, eating $(34 \%)$, getting in or out of bed or a chair $(41 \%)$ and moving about the home (36\%). On the S\&E ADL instrument 52 participants were rated as independent with or without some slowness or difficulty with tasks (S\&E score at least $80 \%$ ), 33 participants not completely independent (S\&E score 50-80\%) and 15 participants very dependent (S\&E score 20-40\%).

\section{Relationships between impairments, activity limitations and HRQOL in Australians living with PD}

Figure 1 demonstrates the relationship between scores on the modified H\&Y and performance on the $6 \mathrm{~m}$ walk test and the TUG. This shows that movement slowness was related to disease severity, with those who were modified H\&Y stage III or higher much more impaired in performing timed gait tests.

For the non-motor impairments, there were moderately strong relationships. Fatigue was common in the cohort with the PFS [21] scores highly correlated with longer duration of PD (PFS Score 1: $\mathrm{r}=0.321, \mathrm{p}<0.01$, PFS Score 2: $\mathrm{r}=0.357, \mathrm{p}<0.001)$ and more severe disease as measured on the modified $\mathrm{H} \& \mathrm{Y}$ scale (PFS Score $1: \mathrm{r}=0.505$, $\mathrm{p}<0.001$, PFS Score 2: $\mathrm{r}=0.499, \mathrm{p}<0.001)$. Fatigue was also correlated with low MMSE scores (PFS Score 1: $\mathrm{r}=-0.343, \mathrm{p}<0.001$, PFS Score 2: $\mathrm{r}=-0.354, \mathrm{p}<0.001)$. There were statistically significant correlations between scores on PFS and the GDS [22] (PFS Score 1: $r=0.653$, $\mathrm{p}<0.001$, PFS Score 2: $\mathrm{r}=0.644, \mathrm{p}<0.000)$. There were also moderately strong correlations between the UPDRS cognition scores and the UPDRS mentation scores (PFS Score 1: $\mathrm{r}=0.562, \mathrm{p}<0.000$, PFS Score 2: $\mathrm{r}=0.559, \mathrm{p}<0.001)$. No statistically significant relationships were found between the MMSE score and the neuropsychiatric inventory total score or the MMSE and the neuropsychiatric inventory depression score.

\begin{tabular}{|l|c|c|c|c|}
\hline Measure & Minimum & Maximum & Mean & St Dev \\
\hline 6m Walk Test (secs) & 3.8 & 17.4 & 6.6 & 2.7 \\
\hline 6m Walk Test (steps) & & 26 & 12.2 & 3.4 \\
\hline TUGT (secs) & 5.6 & 40.2 & 11.8 & 5.8 \\
\hline Motor Section UPDRS & 1 & 49 & 21.4 & 10.8 \\
\hline ADL Section UPDRS & 2 & 35 & 12.7 & 7.1 \\
\hline PDQ39 SI & 0.8 & 72.3 & 25.2 & 18.0 \\
\hline $\begin{array}{l}\text { Schwab and England } \\
\text { (\%) }\end{array}$ & 20 & 100 & 71.6 & 22.7 \\
\hline Euroqol-5D SI & -0.24 & 1.00 & 0.617 & 0.26 \\
\hline EQ VAS & 0.09 & 1.00 & 0.609 & 0.20 \\
\hline
\end{tabular}

St Dev: standard deviation; TUGT: Timed up and go test; UPDRS: United Parkinson Disease Rating Scale; ADL: Activities of Daily Living; PDQ39 SI: Parkinson's Disease Questionnaire Summary Index; EQ VAS: Euroqol Visual Analogue Scale.

aEleven participants used a gait aid to complete the $6 \mathrm{~m}$ Walk Test. bNine participants used a gait aid to complete the TUGT.

Table 3: Motor impairments, activity limitations and health-related quality of life measures.

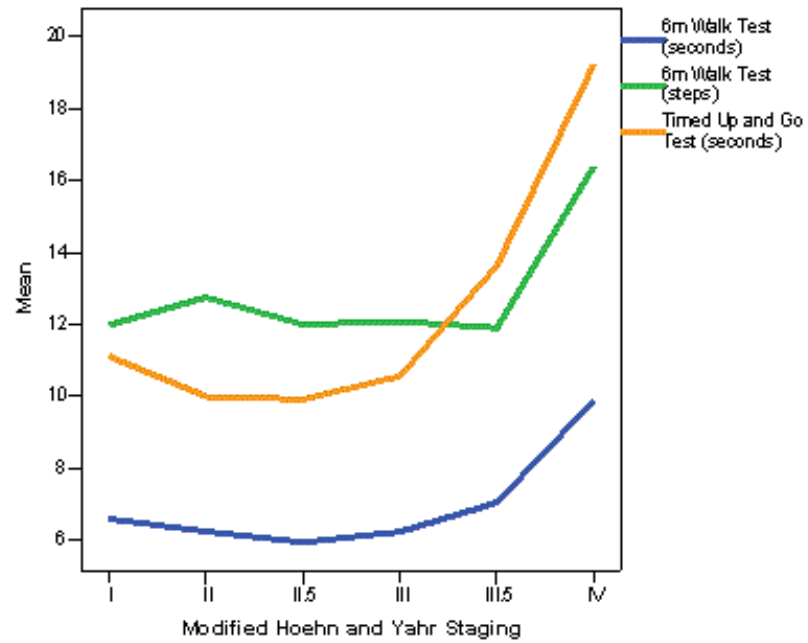

Figure 1: Relationship between disease severity and performance on the $6 \mathrm{~m}$ walk test and the TUG.

Health-related quality of life measures also demonstrated the wide range within the cohort on both the PDQ39SI, the EQ-5D SI (based on UK population-based values from Dolan [23]) and the Euroqol Visual Analogue Scales (EQ VAS) [24]. The mean PDQ-39 SI score for this cohort of Australians living with PD was 25.3 (SD 18.0). Univariate regression analyses showed that disease severity, activity limitations, neuropsychiatric symptom severity, depression and fatigue were significant contributing factors (Table 4). In the multivariate model, 
however, only activity limitations $(\beta=0.55 ; \mathrm{p}=0.000)$, depression $(\beta=0.25 ; p=0.003)$ and fatigue $(\beta=0.18 ; p=0.028)$ appeared to be significant contributing factors. This model accounted for $74 \%$ of the variance in HRQOL as measured by the PDQ-39SI, with activity limitations explaining $30 \%$ of the variability in disease-specific HRQOL.

Three participants reported health states that were valued at or below 0 on the EQ-5D SI. Univariate regression analyses identified disease severity, activity limitations, neuropsychiatric symptom severity, depression and fatigue to be significant predictive factors for generic HRQOL as measured by the EQ-5D SI. However, only activity limitations $(\beta=0.43 ; p=0.001)$ and cognitive impairment $(\beta=-0.23$; $\mathrm{p}=0.010)$ remained significant contributing factors in the multivariate model. This model accounted for $45 \%$ of the variance in EQ-5D SI scores, with activity limitations explaining $18 \%$ and cognitive impairment explaining $5 \%$ of the variability respectively.

\section{Medication profiles}

The medication profile of the participants with PD is summarised in Table 5. The eleven participants not on Levodopa, were recently diagnosed, with a mean H\&Y stage of 1.5 , and minimal reduction in HRQOL (PDQ39 SI of <10). The small number of participants taking dopamine agonists reflected the VCPP philosophy of predominant Levodopa use and reserving the use of dopamine agonists for management of dyskinesia. The mean Levodopa equivalent dose was $756.4 \mathrm{mg}$; however, there was a graded increase in the mean dose when subcategories of disease duration were examined. The mean dose increased to a mean maximum of $1124.9 \mathrm{mg}$ in advanced disease compared to a mean dose of $486.3 \mathrm{mg}$ at disease onset.

\begin{tabular}{|c|c|c|c|c|c|c|c|c|c|c|c|c|}
\hline & \multicolumn{6}{|c|}{ PDQ-39 SI } & \multicolumn{6}{|c|}{ EQ-5D SI } \\
\hline & \multicolumn{3}{|c|}{ Univariate } & \multicolumn{3}{|c|}{ Multivariate $^{1}$} & \multicolumn{3}{|c|}{ Univariate } & \multicolumn{3}{|c|}{ Multivariate $^{1}$} \\
\hline & $\beta$ & $95 \% \mathrm{Cl}$ & R2 & $\beta$ & $95 \% \mathrm{Cl}$ & R2 & $\beta$ & $95 \% \mathrm{Cl}$ & R2 & $\beta$ & $95 \% \mathrm{Cl}$ & R2 \\
\hline Disease severity & 0.58 & $1.55,2.84$ & 33 & 0.06 & $-0.56,0.60$ & 0 & 0.40 & $0.03,0.09$ & 16 & -0.03 & $-0.04,0.03$ & 0 \\
\hline Activity limitation & 0.82 & $1.25,1.68$ & 67 & 0.55 & $0.68,1.30$ & 30 & 0.61 & $0.03,0.06$ & 37 & 0.43 & $0.13,0.05$ & 18 \\
\hline PD duration & 0.08 & $-0.05,0.13$ & 0 & 0.08 & $-0.02,0.09$ & 1 & 0.08 & $-0.00,0.01$ & 1 & 0.14 & $-0.00,0.01$ & 2 \\
\hline $\begin{array}{l}\text { Neuropsychiatric } \\
\text { symptom severity }\end{array}$ & 0.34 & $0.20,0.82$ & 12 & 0.06 & $-0.10,0.26$ & 0 & 0.23 & $0.00,0.03$ & 5 & 0.04 & $-0.01,0.01$ & 0 \\
\hline Depression & 0.69 & $2.94,4.73$ & 48 & 0.25 & $0.49,2.26$ & 6 & 0.52 & $0.08,0.16$ & 27 & 0.14 & $-0.02,0.09$ & 2 \\
\hline Fatigue & 0.67 & $0.07,1.12$ & 45 & 0.18 & $0.00,0.05$ & 3 & 0.54 & $0.00,0.00$ & 29 & 0.21 & $0.00,0.00$ & 4 \\
\hline Cognitive impairment & 0.05 & $-0.83,1.31$ & 0 & 0.01 & $-0.58,0.63$ & 0 & -0.17 & $-0.08,0.01$ & 3 & -0.23 & $-0.08,-0.01$ & 5 \\
\hline
\end{tabular}

Table 4: Univariate and multivariate regression analyses of factors associated with aspects of HRQOL as measured by the PDQ-39 SI and EQ-5D SI.

\begin{tabular}{|l|c|}
\hline Medication & Frequencies (\%) \\
\hline No PD medications & 11 \\
\hline Levodopa only & 59 \\
\hline Combination therapya & 30 \\
\hline Psychotropic Medication & 49 \\
\hline Antidepressant Medication & 20 \\
\hline aLevodopa+COMT inhibitor. & \\
\hline
\end{tabular}

were consistently mobile, with $18 \%$ experiencing period of slowing of mobility. Abnormal involuntary movements such as tremor and dyskinesia were reported by only $17 \%$ of participants.

\section{Social context, caregiver profile and caregiver burden}

Table 6 summarises the caregiver profile and burden of care. External service supports were limited in the majority of the cohort, with the major support relating to domestic assistance (54\%). This was provided predominantly by private arrangement $(26 \%)$ and to a lesser degree by support organisations (20\%). Meal provision was the second most common support service provided (14\%). This was equally provided by family friends (6\%) and support organisations (6\%). The majority of participants did not require any other external assistance. Univariate regression analysis identified that disease severity $(\beta=0.40$; $\mathrm{p}=0.000)$ and partners who were caregivers $(\beta=0.23 ; \mathrm{p}=0.028)$ were significant predictors for generic HRQOL as measured by the EQ-5D SI. In the multivariate model, however, only disease severity appeared to be the significant contributing factor $(\beta=0.39 ; \mathrm{p}=0.000)$ explaining $15 \%$ of the variance in EQ-5D SI scores. 
Page 6 of 7

\begin{tabular}{|l|l|}
\hline Characteristic & Frequency \\
\hline Sex (male) (\%) & 30 \\
\hline $\begin{array}{l}\text { Relationship to recipient } \\
\text { Spouse (\%) } \\
\text { Child (\%) }\end{array}$ & 60 \\
\hline Age (mean (SD), years) & 19 \\
\hline Main language English (\%) & $60.3(14.5)$ \\
\hline Living with recipient of care (\%) & 81 \\
\hline Continuing to work (\%) & 70 \\
\hline Change in income due to caregiver role (\%) & 30 \\
\hline Receiving social benefits (\%) & 32 \\
\hline Average time in role (years) & 47 \\
\hline $\begin{array}{l}\text { Average number of hours of care by caregiver } \\
\text { Per day (hours) } \\
\text { Further available hours (hours) }\end{array}$ & 4.5 \\
\hline Average additional family assistance (hours) & 2.5 for 63\% of recipients \\
\hline $\begin{array}{l}\text { *Six participants did not have a caregiver. Results presented for 94 participants } \\
\text { only. }\end{array}$ \\
\hline
\end{tabular}

Table 6: Caregiver profile*.

\section{Discussion}

This cohort study documents the profile of impairments, activity limitations, HRQOL, medication usage and care requirements of people living with Parkinson's disease referred to a service offering a comprehensive care model. This large cohort of people with PD were mostly living at home, with a relative, and were troubled by the effects of co-morbidities as reflected by the predominance of the older age group. Most were on Levodopa or other PD medications, with overall good control of mobility with minimal dyskinesias. Cognition was intact in most individuals in this sample, with minimal evidence of depression or neuropsychiatric complaints. The majority of participants were independent in ADL and although HRQOL was impaired, life quality was relatively high compared to other international published studies $[25,26]$.

This relatively high HRQOL, compared to other publications, as well as the high level of community living with minimal disruption to family life paints a different profile to that which is commonly promulgated by the pathology and impairment literature [27-30]. Despite this, HRQOL was found to be associated with disease severity, limitations in performing ADL, depression and fatigue. This concurs with the findings of Soh et al. [31] and highlights the need to take these factors into consideration in order to minimise the functional consequences of PD. Strong relationships were also observed between motor impairments and activity limitations, confirming the findings by Tan et al [30]. This provides further supportive evidence that screening for impairments including postural instability, gait hypokinesia and freezing may help to optimise functional outcomes. Finally, and not surprisingly, medication requirements increased according to disease progression. The impact of this increasing

dependence on medication over time on the life quality and ability of the person with PD to perform ADL warrants further investigation.

Although the type of caregiver was not found to be a significant contributor to HRQOL, it was found that if care was provided by the partner, generic HRQOL was likely to better than when care was provided by a family member or friend. Programs to assist and promote the role of the carer with respite provisions have been recognised to be important aspects of the comprehensive care model [32]. Sustaining the HRQOL of the caregiver is no less important than for the person with $\mathrm{PD}$ and would benefit from further study to understand the needs of the caregiver in the provision of their role, in particular the age, gender and health status of the caregiver.

In this study, in-depth analyses of individuals with PD living in community support facilities were not feasible due to the limited number of participants recruited (7\%). It is important to note, however, that participants in this sample who lived in care facilities were more severely impaired, and the caregiver burden was higher. A larger sample characterising PD patients across a variety of settings including residential care is therefore warranted. It may also be useful to include measures of wellbeing in future investigations in order to determine how these individuals may be satisfied with their personal life and social situation [33,34].

The main limitation of this study was that participants were limited to individuals with mild to moderate disease. Given that individuals with advanced disease (H\&Y Stage 5) were not included in the sample, these findings may not necessarily be generalised to this subgroup. Whilst further work is required to examine the profile of a broader sample of people living with $\mathrm{PD}$, this study has provided a snapshot of the health status of a cohort of individuals with PD and their caregivers. This information forms a foundation on which future studies can compare the efficacy of different models of care on people living with this debilitating condition.

To conclude, this report provides a representative snapshot, including caregiver role, of a diverse group of people with PD across a wide domicile, a wide range of severity and disease durations. In all, it describes a very benign picture for such a diverse group.

\section{Acknowledgements}

This project has been funded by a National Parkinson Foundation Centre Research grant. The authors thank Tracy Taylor, Catherine Williams and Romi Haas for their dedicated contributions to trial coordination.

\section{References}

1. Wickremaratchi MM, Knipe MD, Sastry BS, Morgan E, Jones A, et al. (2011) The motor phenotype of Parkinson's disease in relation to age at onset. Mov Disord 26: 457-463.

2. Muangpaisan W, Mathews A, Hori H, Seidel D (2011) A systematic review of the worldwide prevalence and incidence of Parkinson's disease. J Med Assoc Thai 94: 749-755.

3. Aminoff MJ, Christine CW, Friedman JH, Chou KL, Lyons KE, et al. (2011) Management of the hospitalized patient with Parkinson's disease: current state of the field and need for guidelines. Parkinsonism Relat Disord 17: 139-145.

4. Hallett M (1993) Physiology of basal ganglia disorders: an overview. Can J Neurol Sci 20: 177-183. 
Citation: Morris EM, Murphy AT, Watts JJ, Jolley D, Campbell D, et al. (2015) The Health Profile of People Living with Parkinson's Disease Managed in a Comprehensive Care Setting. Aging Sci 3: 135. doi:10.4172/2329-8847.1000135

Page 7 of 7

5. Camicioli R, Majumdar SR (2010) Relationship between mild cognitive impairment and falls in older people with and without Parkinson's disease: 1-Year Prospective Cohort Study. Gait Posture 32: 87-91.

6. Sullivan KL, Ward CL, Hauser RA, Zesiewicz TA (2007) Prevalence and treatment of non-motor symptoms in Parkinson's disease. Parkinsonism Relat Disord 13: 545.

7. Iansek R (1999) Key points in the management of Parkinson's disease. Aust Fam Physician 28: 897-901.

8. Iansek R (1999) Interdisciplinary rehabilitation in Parkinson's disease. Adv Neurol 80: 555-559.

9. Wade DT, Gage H, Owen C, Trend P, Grossmith C, et al. (2003) Multidisciplinary rehabilitation for people with Parkinson's disease: a randomised controlled study. J Neurol Neurosurg Psychiatry 74: 158-162.

10. Folstein MF, Folstein SE, McHugh PR (1975) "Mini-mental state". A practical method for grading the cognitive state of patients for the clinician. J Psychiatr Res 12: 189-198.

11. Hoehn MM, Yahr MD (1967) Parkinsonism: onset, progression and mortality. Neurology 17: 427-442.

12. Bauso DJ, Tartari JP, Stefani CV, Rojas JI, Giunta DH, et al. (2012) Incidence and prevalence of Parkinson's disease in Buenos Aires City, Argentina. Eur J Neurol 19: 1108-1113.

13. Bhidayasiri R, Wannachai $\mathrm{N}$, Limpabandhu S, Choeytim S, Suchonwanich Y, et al. (2011) A national registry to determine the distribution and prevalence of Parkinson's disease in Thailand: implications of urbanization and pesticides as risk factors for Parkinson's disease. Neuroepidemiology 37: 222-230.

14. Morris ME, Watts JJ, Iansek R, Jolley D, Campbell D, et al. (2009) Quantifying the profile and progression of impairments, activity, participation, and quality of life in people with Parkinson disease: protocol for a prospective cohort study. BMC Geriatr 9: 2.

15. Goetz CG, Poewe W, Rascol O, Sampaio C, et al. (2004) Movement Disorder Society Task Force report on the Hoehn and Yahr staging scale: Status and recommendations. Mov Disord 19: 1020-1028.

16. Marsden CD, Fahn S (eds.) (1997) Movement Disorders 2. Butterworth \& Co. Ltd., London.

17. Sullivan MT (2007) Caregiver Strain Index (CSI). Urol Nurs 27: 251-252.

18. Podsiadlo D, Richardson S (1991) The timed "Up \& Go": a test of basic functional mobility for frail elderly persons. J Am Geriatr Soc 39: 142-148.

19. Morris S, Morris ME, Iansek R (2001) Reliability of measurements obtained with the Timed "Up \& Go" test in people with Parkinson disease. Phys Ther 81: 810-818.

20. McRae C, Diem G, Vo A, O'Brien C, Seeberger L (2002) Reliability of measurements of patient health status: a comparison of physician, patient, and caregiver ratings. Parkinsonism Relat Disord 8: 187-192.
21. Herlofson K, Larsen JP (2002) Measuring fatigue in patients with Parkinson's disease - the Fatigue Severity Scale. Eur J Neurol 9: 595-600.

22. Yesavage JA, Brink TL, Rose TL, Lum O, Huang V, et al. (1982) Development and validation of a geriatric depression screening scale: a preliminary report. J Psychiatr Res 17: 37-49.

23. The Euroqol Group (1990) EuroQol - a new facility for the measurement of health-related quality of life. Health Policy 16: 199-208.

24. Dolan P (1997) Modeling valuations for EuroQol health states. Med Care 35: 1095-1108.

25. Raggi A, Leonardi M, Covelli V, Albanese A, Soliveri P, et al. (2012) Concordance between severity of disease, prevalence of nonmotor symptoms, patient-reported quality of life and disability and use of medication in Parkinson's disease. Neurol Sci 33: 847-853.

26. Leonardi M, Raggi A, Pagani M, Carella F, Soliveri P, et al. (2012) Relationships between disability, quality of life and prevalence of nonmotor symptoms in Parkinson's disease. Parkinsonism Relat Disord 18: 35-39.

27. Morris ME, Iansek R, Kirkwood B (2009) A randomized controlled trial of movement strategies compared with exercise for people with Parkinson's disease. Mov Disord 24: 64-71.

28. Iansek R, Danoudis M (2012) Oral formulations of L-dopa and continuous dopaminergic stimulation. Mov Disord 27: 579.

29. Hely MA, Morris JG, Reid WG, Trafficante R (2005) Sydney Multicenter Study of Parkinson's disease: non-L-dopa-responsive problems dominate at 15 years. Mov Disord 20: 190-199.

30. Tan D, Danoudis M, McGinley J, Morris ME (2012) Relationships between motor aspects of gait impairments and activity limitations in people with Parkinson's disease: a systematic review. Parkinsonism Relat Disord 18: 117-124.

31. Soh SE, Morris ME, McGinley JL (2011) Determinants of health-related quality of life in Parkinson's disease: a systematic review. Parkinsonism Relat Disord 17: 1-9.

32. van der Eijk M, Faber MJ, Al Shamma S, Munneke M, Bloem BR (2011) Moving towards patient-centered healthcare for patients with Parkinson's disease. Parkinsonism Relat Disord 17: 360-364.

33. Soh SE, McGinley J, Morris ME (2011) Measuring quality of life in Parkinson's disease: selection of-an-appropriate health-related quality of life instrument. Physiotherapy 97: 83-89.

34. Cubí-Mollá P, de Vries J, Devlin N (2014) A study of the relationship between health and subjective well-being in Parkinson's disease patients. Value Health 17: 372-379. 